\title{
HALLAZGOS MONETARIOS DE 1765 A 1831 EN TOLEDO, SEVILLA, ASTURIAS, CUENCA, MADRID, BURGOS ALBACETE Y VALENCIA, DONADOS A LA REAL ACADEMIA DE LA HISTORIA
}

\author{
COIN FINDS FROM 1765 TO 1831 IN TOLEDO, SEVILLE, ASTURIAS, CUENCA, MADRID, BURGOS \\ ALBACETE AND VALENCIA, DONATED TO THE ROYAL ACADEMY OF HISTORY
}

\author{
JUAN MANUEL ABASCAL PALAZÓN \\ Universidad de Alicante
}

ANTONIO ALBEROLA BELDA

El Gabinete de Antigüedades de la Real Academia de la Historia conserva un importante volumen de documentación escrita, referente a descubrimientos, hallazgos casuales y donaciones de monedas desde su fundación hasta bien entrado el siglo $\mathrm{XX}^{1}$. De esos documentos, agrupados en el archivo bajo la denominación de "Documentos del numario" se dio a conocer el inventario hace unos años (Martín, Cepas y Canto, 2004).

La revisión parcial de ese fondo, que realizamos en el año 2010, tenía por objeto la localización de noticias que pudieran dar información complementaria sobre la colección que perteneció en el siglo XVI a Ambrosio de Morales y que se fue desmembrando posteriormente hasta desaparecer.

Si el objetivo principal no proporcionó ningún resultado, pese a que estos documentos se refieren fundamentalmente a la colección propia de la Academia y a la catalogación de fondos ajenos, tuvimos la oportunidad de identificar diversas noticias de hallazgos monetarios realizados en diferentes puntos de España entre mediados del siglo XVIII y las primeras décadas del XIX, que fueron entregados a la propia Academia, donde se catalogaron y guardaron en su monetario. Se trata de noticias aisladas, en ocasiones referidas a lugares de donde no tenemos otras evidencias de antigüedad y que por ello tienen el máximo interés.

Los datos que aparecen en las páginas que siguen se refieren sólo a hallazgos casuales y se excluyen las donaciones de monedas cuyo origen no pudo precisarse en su momento o que formaban parte de colecciones, ya que nuestro propósito sólo es añadir a la literatura científica nuevas referencias sobre hallazgos de moneda antigua en Hispania. A los datos obtenidos de los expedientes del Numario hemos añadido algunas

1. La redacción de este trabajo se ha realizado en el marco del programa HAR2009-09104 (subprograma HIST) del Ministerio de Ciencia e Innovación del Gobierno de España. noticias que se encuentran en las Actas de las juntas ordinarias de la propia Academia.

En cada una de las entradas se identifica inicialmente el lugar o lugares de hallazgo, la fecha del descubrimiento cuando se conoce y la referencia al expediente del Numario de la Real Academia de la Historia en el que se conservan los documentos.

\section{OROPESA (TOLEDO). 1765. GN 1765/1. Figura 1}

Carta de Antonio Alarcón, vecino de Oropesa, a Nicolás de Mejorada²:

“Mi amigo y señor: Me alegraré que Vmd. se mantenga con toda felicidad y así mismo con el buen despacho de sus dependencias. No puedo menos de noticiar a Vmd., por si se halla Don Ignacio Hermosilla $^{3}$ en esa Corte, cómo en uno de los días de la semana pasada un vecino de la villa de Lagartera, yendo a ver un asiento de colmenas que tiene en la jurisdicción desta villa, en un jaral que hacía un barranco se encontró 6 libras y seis onzas de unas monedas que cada una pesa una onza, de las que se demuestra ser de tiempo de César Augusto por los caracteres. Son de bronce por el un lado y por

2. Citada en Martín, Cepas y Canto, 2004, 98.

3. Ignacio Hermosilla de Sandoval y Rojas (Llerena, 1720? Madrid, 29 de noviembre 1794). Presbítero y colegial del Imperial de San Miguel en Granada, fue primer oficial de la Secretaría del Despacho Universal de Indias (1776) y del Consejo de Indias (1785). Perteneció desde 1752 a la Real Academia de la Historia -en la que fue censor (1754-1755 y 1767-1769) y secretario interino por breve tiempo en 1763y a la Real Academia de Bellas Artes, en la que fue Secretario general (1753-1776). Su popularidad científica se debe a los meticulosos estudios sobre Talavera la Vieja (Augustobriga) (Hermosilla, 1796) y Vascos. Sobre su figura, cf. VargasZúñiga, 1978, 45. 

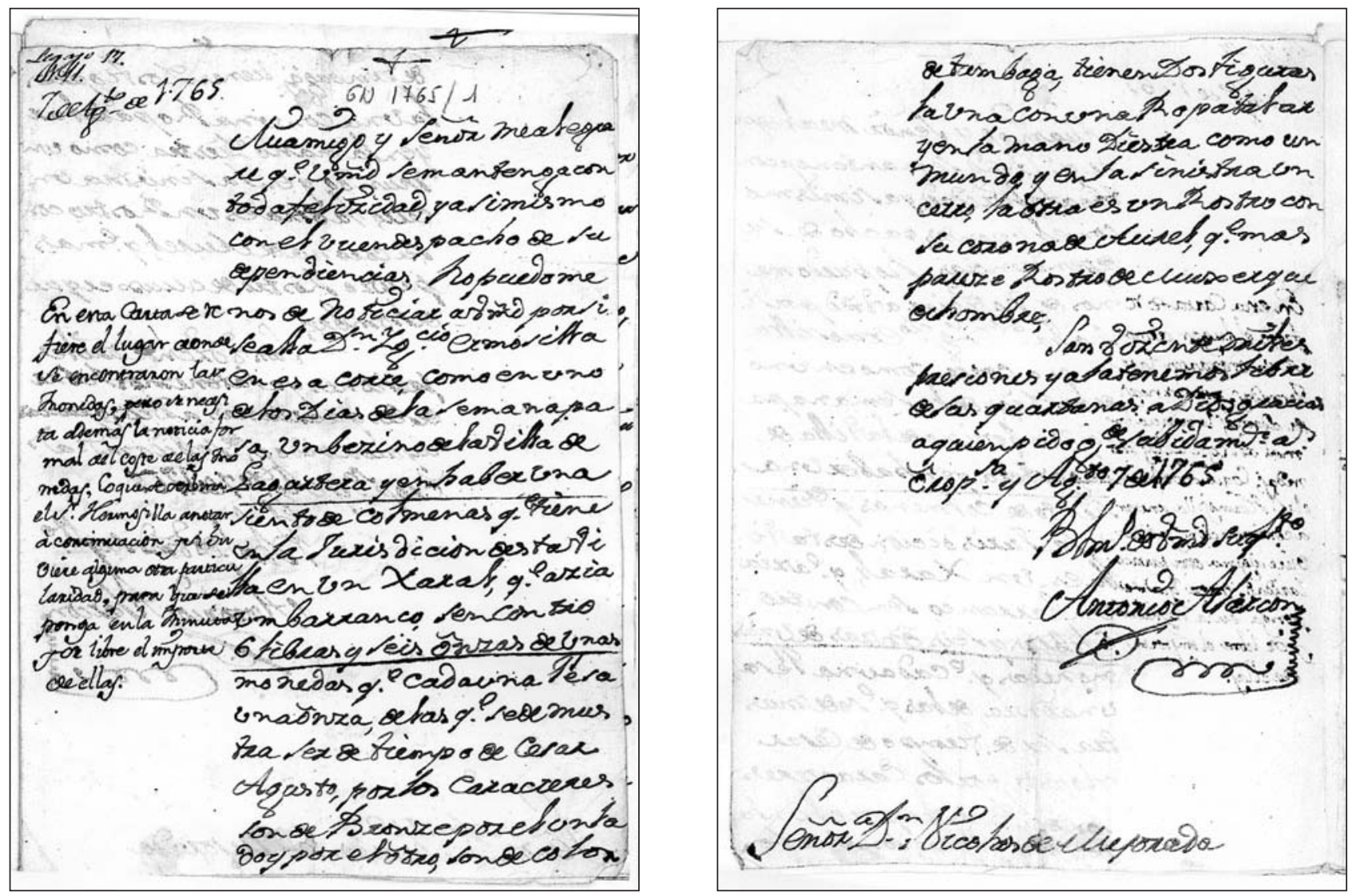

Figura 1: Carta de Antonio Alarcón (GN 1765/1) sobre las monedas de Oropesa.

el otro son de color de tambaga ${ }^{4}$; tienen dos figuras, la una con una ropa talar y en la mano diestra como un mundo y en la sinistra un cetro; la otra es un rostro con su corona de laurel, que más parece rostro de mujer que de hombre.

Don Vicente, mil expresiones; ya lo tenemos libre de las cuartanas, a Dios gracias, a quien pido guarde su vida muchos años.

Oropesa, y agosto 7 de 1765 .

B(esa) 1(a) m(ano) de Vmd. su [ilegible]

Antonio Alarcón [rubricado] Señor Don Nicolás de Mejorada"

[Al margen]: En esta carta se refiere el lugar donde se encontraron las monedas pero se necesita, además, la noticia formal del coste de las monedas, lo que se servirá el Sr. Hermosilla anotar a continuación, y si hubiere alguna otra particularidad, para que se ponga en la minuta y se libre el importe de ellas.

El peso indicado para las monedas son 6 libras (x 16 onzas) y 6 onzas, lo que equivale -según el peso individual de cada pieza que se indica en el texto- a unas 102 monedas. Por la descripción podría tratarse de un

4. ¿Támbara? tesorillo de bronces datable entre mediados del siglo II y comienzos del siglo III.

\section{EL CORONIL (SEVILLA). 1780. GN 1780/3. Figura 2}

Carta de Juan Cano Guerrero a José Miguel de Flores ${ }^{5}$.

[Sobrecubierta]: A Don Joseph Miguel de Flores ${ }^{6}$, del colegio de abogados desta villa y Corte de Madrid, guarde Dios m(ucho)s a(ño)s.

"Sr. Don José Miguel de Flores.

Muy señor mío: Están en mi poder dos medallas encontradas en este término, una de oro y otra de plata; la de oro tiene de peso 4 adarmes; por un lado señala el rostro del emperador Aurelio y por el otro un cuerpo entero del ídolo; en una mano,

5. Citada en Martín, Cepas y Canto, 2004, 133.

6. José Miguel de Flores y de la Barrera, fallecido el 23 de febrero de 1790. Miembro del Consejo de Castilla y alcalde de Casa y Corte. Ingresó en la Academia en 1748 y fue su Secretario entre el 16 de junio de 1769 y el 11 de diciembre de 1789, en que se jubiló; fue también Censor desde el 6 de julio de 1764 al 11 de julio de 1765, fecha en que fue sustituido por Martín de Ulloa. Cf. Anónimo, 1796, p. CXLVIII y Anuario de la Real Academia de la Historia, 2008, 108 y 122. 


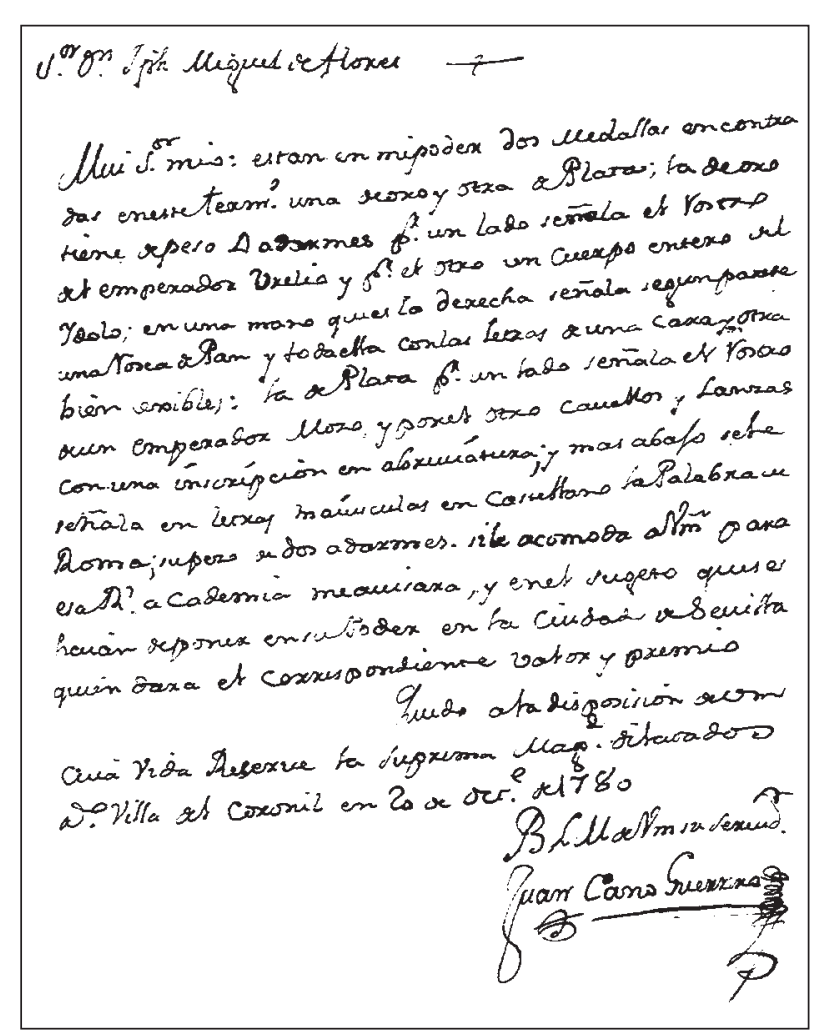

Figura 2: Carta de Juan Cano Guerrero (GN 1780/3) sobre las monedas de El Coronil.

que es la derecha, señala según parece una rosca de pan y toda ella con las letras de una cara y otra bien legibles. La de plata por un lado señala el rostro de un emperador mozo y, por el otro, caballos y lanzas con una inscripción en abreviatura; y más abajo se le señala en letras mayúsculas en castellano la palabra de Roma; su peso de dos adarmes. Si le acomoda a Vm. para esa Real Academia, me avisará y en el sujeto que se hayan de poner en su poder en la ciudad de Sevilla, quien dará el correspondiente valor y premio.

Quedo a la disposición de Vm. cuya vida reserve la suprema majestad dilatados años.

Villa del Coronil en 20 de octubre de 1780.

B(esa) 1(a) m(ano) de Vm. su servidor

\section{Juan Cano Guerrero [rubricado]."}

La descripción del autor es incomprensible para la moneda de oro, aunque por el peso que indica, el doble que la de plata, debería estar en torno a los 7/8 gramos y podría tratarse de un áureo de época severiana, monedas en las que el elemento Aurelius de la titulatura imperial aparece con frecuencia. La de plata parece ser un denario romano del siglo II a.C., con cabeza de Roma en el anverso y los Dioscuros en el reverso; en el exergo, ROMA.

\section{ASTURIAS. 1788. GN 1788/2(2)}

Informe autógrafo de José de Guevara Vasconcelos ${ }^{7}$ sobre varias monedas descubiertas en Asturias y donadas a la Academia por Jovellanos ${ }^{8}$ :

"Ilmo. Sr.:

He examinado las diez y siete monedas que regaló para nuestro monetario el señor Don Gaspar de Jovellanos, hallándose en el Principado de Asturias, y que V.S.I. mandó en la Junta anterior se me entregasen para que las explicara y colocara en sus respectivas series y, en cumplimiento de este acuerdo, las he examinado y son las siguientes:

Cuatro de ellas de mediano bronce, la una de regular conservación y las tres mal conservadas, las aplican los anticuarios a Cádiz, porque tienen por el anverso la cabeza de Hércules cubierta con la piel del león y sobre el hombro la clava ${ }^{9}$, sin inscripción o leyenda alguna, y por el reverso dos atunes a la derecha, encima y debajo letras desconocidas, que algunos pretenden se han de leer con esta interpretación: DOMINATOR. GADIVM $=\mathrm{M}$. BaHaL AGaDIR. En nuestro monetario tenemos varias de estas bien conservadas pero no son comunes fuera de España; las han publicado el M. Flórez, Medallas, tomo $2 .^{\circ}$, tab. 27 , núm. $^{\circ} 4 .^{\circ}$, pág. 442 y Don Luis Velázquez, Ensayo, tab. 17, n. ${ }^{\circ} 11$, pág. 149.

Una de Carmona, que por el anverso tiene $\mathrm{Ca}$ beza varonil sobre su izquierda, con morrión y penacho, $y$ en el reverso CARMO entre dos rayas y dos espigas a la izquierda. Es de buena conservación y, aunque tiene nuestro monetario muchas de este mismo tipo, se colocará entre las duplicadas para que se ofrezca algún cambio. La publicó el $\mathrm{P}$. M. Flórez, Medallas, tomo 1. ${ }^{\circ}$, tab. 14, núm. 8, pág. 288 y la refiere Gúseme, Diccion. ${ }^{\circ}$ voz Carmo, n. ${ }^{\circ}$ $1 .^{\circ}$, pág. 102.

Una en pequeño bronce mal conservada que, por el anverso, tiene la cabeza de Apolo sobre su izquierda con el pelo en trenzas o bucles rizados y por el reverso buey y, sobre él, media luna.

7. José de Guevara Vasconcelos (Ceuta, 1737 - Madrid, 1804). Doctor en Teología y con buen conocimiento del mundo clásico, fue "Caballero de la Orden de Santiago, del Consejo de S. M. en el Real de las Órdenes, Ministro de la Real Junta general de Comercio, Moneda y Minas y Canónigo de la Sta. Metropolitana Iglesia de Zaragoza" (Gazeta de Madrid n. ${ }^{\circ}$ 97, 4 de diciembre de 1804). Censor perpetuo de la Real Sociedad Matritense de Amigos del País y miembro de la Real Academia Española, entre otros muchos puestos que su excelente fama de orador le granjeó. En la Real Academia de la Historia fue anticuario (1775-1798) censor (1799-1802), y archivero (1794-1804). De su actividad académica han quedado muchísimas documentos. Sobre su figura, cf. principalmente Almagro-Gorbea, 1999, 124-126; Maier, 2003, 450-451; Abascal y Cebrián, 2010, nota 305.

8. Citada en Martín, Cepas y Canto, 2004, 149.

9. Se transcriben en cursiva los subrayados del original. 
Atribúyense estas medallas a Obulco, pues otras de semejantes tipos tienen las letras OBVL y NIC, que interpreta el P. Flórez Obulco Nova Invicta Civitas, haciendo las tres letras del NIC iniciales de las tres últimas dicciones. La tiene la Academia y las publicaron el M. Flórez, tab. 34, n. ${ }^{\circ}$ 7, Valdeflores, Ensayo, tab. 12, n. ${ }^{\circ} 2$ y 3 y la refiere Gúseme voz Obulco.

Una en pequeño bronce de mediana conservación, que pertenece a la ciudad de Constantinopla; por el anverso tiene cabeza de mujer con galea, en la sinistra lanza al hombro y la inscripción CONSTANTINOPOLIS; por el reverso, Victoria en pie sobre proa de nave, en la derecha lanza o dardo, en la siniestra clípeo, en el exergo MKB, que interpreta a su modo Harduino: Mercatores Kartaginenses, etc. Es común, las tiene la Academia muy bien conservadas; las han publicado los anticuarios que nos han dado las monedas de pueblos y ciudades y la refiere Gúseme, Diccion. ${ }^{\circ}$ voz Constantinopla.

Dos de mediano bronce, mal conservadas, del emperador Tiberio Claudio que por el anverso tienen la cabeza del emperador desnuda sobre su izquierda y, en el reverso, la figura de Palas con morrión; en la derecha, dardo; en la izquierda, escudo. Las inscripciones están borradas pero deben ser las siguientes: Tiberius CLAVDIVS CAESAR AVGVSTVS Pontifex Maximus Tribunitia Potestate Pater Patriae y, en el reverso, Senatus Consulto. Son estas monedas muy comunes y las tiene la Academia multiplicadas, de excelente conservación.

Una de gran bronce y mala conservación pero, aunque sus inscripciones y tipos están borrados, se conoce que por el anverso tiene la cabeza del emperador con láurea sobre su izquierda y la leyenda IMPerator CAESar DOMITianus AVGustus GERManicus Pontifex Maximus COS (id est) Consul XVII CENSor PERPetuus Pater Patriae y, por el reverso, Júpiter sentado con lanza en la derecha y victoriola en la siniestra y la leyenda IOVI VICTORI; en el exergo, Senatus Consulto. Es común, las tiene la Academia de excelente conservación en grande y mediano módulo y la han publicado $\mathrm{Mu}$ selio tab. 51, n. ${ }^{\circ}$ 10, Tiepolo, Mesabarba, Gúseme y se halla en todos los anticuarios.

Dos en mal bronce y mal conservadas, de Trajano; la una tiene por el anverso la cabeza del emperador la láurea, sobre su izquierda, y la leyenda IMPeratori CAESari NERVAE TRAIANO AVGusto GERmanico DACico Pontifici Maximo TRibunitia Potestate COS (id est) Consuli V Patri Patriae y, por el reverso, Senatus Populusque Romanus OPTIMO PRINCIPI, una Victoria apoyando sobre una columna un escudo en el cual escribe VICtoria DACica; a los lados, Senatus Consulto. Es común y las tiene nuestro monetario de excelente conservación. Las han publicado los anticuarios Muselio, Mesabarba, Tiepolo, Gúseme, etc. La otra es del mismo emperador, con el mismo anverso e inscripciones, pero el reverso es mujer en pie con cornucopia en la izquierda y flor en la derecha, que también la tiene la Academia y es común y publicada por los anticuarios.

Una que parece de Antonino Pío pero tan mal conservada que no se descubren ni vestigios de las leyendas.

Una de mediano bronce y con poca conservación, que pertenece a Marco Aurelio Antonino; por el anverso, su cabeza barbada, con láurea, sobre su izquierda, y la leyenda Marcus ANTONINVS AVGustus ARMENIACVS y por el reverso TRibunitia Potestate XX IMPerator IIII COS (id est) Consul III Senatus Consulto; Victoria en pie; en la derecha, palma, en la siniestra apoyada en un trofeo. No es común pero la tiene la Academia, bien que poco mejor conservada que la presente y aun entre las dos no se puede completar toda la lectura de las inscripciones; la publicó Mesabarba, pág. 223.

Tres del bajo imperio, en pequeño módulo, muy mal conservadas; la una parece que es Claudio Gótico con su cabeza con corona radiada y por el reverso un águila y la leyenda CONSECRATIO. La otra es de Constantino Magno pero de tan mala conservación que no es posible leer la inscripción y la 3. ${ }^{\text {a }}$ de Constancio; por el anverso tiene la cabeza del emperador con diadema de perlas y la inscripción Dominus Noster CONSTANTIVS Pius Felix AVGustus y, por el reverso, el emperador armado con escudo y lanza que vibra contra un jinete medio derribado de su caballo y la inscripción FELix TEMPorum REPARATIO; en el exergo, CONOB que, según la interpretación de Harduino, son iniciales de Civitates Omnes Narbonenses Obtulerunt.

Todas tres son muy comunes y las publican los anticuarios. La Academia las tiene bien conservadas.

Esta es, Ilmo. señor, la explicación sucinta de las 17 monedas que se me entregaron en la Junta anterior y que, en virtud del acuerdo de V.S.I. he procurado examinar con cuidado, cotejándolas cada una con las de nuestro Gabinete; pero no puedo menos de advertir que es raro se hayan hallado en Asturias monedas de las colonias y municipios de la Bética. Si juzgase V.S.I. que es necesaria mayor ilustración, estoy pronto a darla. Madrid y marzo 5 de 1788.

José de Guevara Vasconzelos [rubricado]"

Las monedas a que se refiere el informe son las siguientes:

1-4. GADIR. Unidad. Siglos II-I a.C.

A. Cabeza de Melqart cubierta con la piel de león; sobre el hombro o detrás, clava.

R. Dos atunes a la izquierda; encima y debajo, inscripciones neopúnicas.

$R A H$, pp. 59-67. 
5. CARMO. As, Mediados del siglo II a.C.

A. Cabeza masculina con casco de penacho, a derecha; alrededor, láurea.

R. Dos espigas a izquierda; a la derecha, entre ellas y entre líneas, leyenda CARMO.

CNH, pp. 382-383. Para la identificación, compárese con Flórez, tomo $1^{\circ}$, tab. 14, n. ${ }^{\circ}$, pág. 288.

6. OBULCO. Semis. Siglo I a.C.

A. Cabeza de Apolo a derecha con posibles leyendas OBVL delante y NIG detrás.

$\mathrm{R}$. Toro a derecha; encima, creciente (con variantes de leyenda $\mathrm{CN}$ ó $\mathrm{NIG})$.

CNH, p. 352, n. $.^{\circ} 79-86$. En la descripción del anverso, el autor indica "cabeza de Apolo sobre su izquierda", lo que significa que a derecha desde el punto de vista del espectador.

7. SERIES URBANAS, período 1. ${ }^{\circ}$. Nummus. CYZICO, of. 2. ${ }^{\text {a } ~ 330-336 ~ d . C . ~}$

A. CONSTAN-TINOPOLI. Busto a izquierda, con casco, manto imperial y lanza invertida.

R. Victoria de pie, a izquierda sobre proa de nave, con lanza y escudo.

Exergo: [(-)s]MKB $[(\cdot)]$

RIC VII, pp. 653-658.

8-9. CLAUDIO. As. ROMA o ceca local. 41-54 d.C.

A. [ti claudius caesar aug $\mathrm{p} m$ tr $\mathrm{p}$ imp (p p)]. Cabeza desnuda, a izquierda.

R. S - C. Minerva, con lanza y escudo, a derecha.

RIC I ${ }^{2}, 100 / 116$.

10. DOMICIANO. Sestercio. ROMA. 95-96 d.C

A. [imp caes domit aug germ cos XVII cens per p p]. Cabeza laureada, a derecha.

R. IOVI VICTORI. Júpiter sentado a izquierda, sosteniendo victoriola y cetro.

Exergo: S C.

RIC II, 412. La clasificación debe hacerse con reservas, pues el autor, tras indicar que las inscripciones y tipos están borrados, indica el consulado, añadiendo un pontificado máximo en la leyenda que no existe. Con ese reverso existen piezas de varios consulados y diferente cronología. Por otra parte, el reverso sigue siendo común en monedas del siglo II.

11. TRAJANO. Sestercio. ROMA. 103-111 d.C. A. IMP CAES NERVAE TRAIANO AVG GER DAC P M TR P COS V P P. Cabeza laureada, a derecha. R. S P Q R OPTIMO PRINCIPI, S - C. Victoria de pie, a derecha, atando un escudo con la inscripción VIC DAC a un tronco de palmera.

RIC II, 527 ó 528 (der.), 530 (izq.).

12. TRAJANO. Sestercio. ROMA. 103-111 d.C. A. IMP CAES NERVAE TRAIANO AVG GER DAC P M TR P COS V P P. Cabeza laureada, a derecha.
R. S P Q R OPTIMO PRINCIPI, S - C. Figura femenina en pie, a izquierda (Abundantia o Pax) sosteniendo espigas o rama con su mano derecha y cornucopia en la izquierda.

RIC II, p. 280. El autor indica "flor" en la mano derecha, lo que hay que entender como espigas o rama. No puede tratarse de Spes por la presencia de la cornucopia.

13. Una que parece de Antonino Pío pero tan mal conservada que no se descubren ni vestigios de las leyendas.

14. MARCO AURELIO. As o dupondio. ROMA. 166 d.C.

A. M ANTONINVS AVG ARM [parth max]. Cabeza a derecha.

R. TR P XX IMP IIII COS III S C. Victoria en pie, sosteniendo palma y colocando escudo sobre tronco de palmera; en el escudo, la inscripción VIC PAR y, en la base, armas.

RIC III, p. 287. No es exacta la leyenda de anverso que proporciona el autor; con todas las reservas, la pieza más parecida a sus comentarios, en los que atribuye la moneda a Antonino Pío, es la descrita.

15. CLAUDIO II. Antoniniano. ROMA o ceca local. Circa 270 d.C.

A. [divo Claudio]. Cabeza radiada, a derecha.

R. CONSECRATIO. Águila.

Tipo RIC V.1, 266.

16. La otra es de Constantino Magno pero de tan mala conservación que no es posible leer la inscripción.

17. CONSTANCIO II. Nummus. CONSTANTINOPLA, of. 2. ${ }^{\text {a } ~ 351-361 ~ d . C . ~}$

A. D N CONSTANTIVS P F AVG. Busto con diadema de perlas, drapeado y con coraza, a derecha.

R. FEL TEMP REPARATIO. Soldado a izquierda, alanceando a jinete caído.

Exergo: CONSB $[(-)]$

RIC VIII, pp. 458/460. El autor lee en el exergo CONOB, sin duda por error; hay que pensar que se trata de una emisión de Constantinopla con este exergo, que es el más similar en el tipo que describe de las series de Falling horseman.

\section{NORTE DE LA PROVINCIA DE CUENCA. 1791}

Acta de la Junta ordinaria de 15 de abril de 1791 .

"Leí una carta de nuestro académico D. Jácome Capistrano de Moya ${ }^{10}$, cura de la Fuente de

10. Jácome Capistrano de Moya (Pinarejo, Cuenca, 1737 Fuente de Pedro Naharro, 1815). Arcediano de Moya y párroco de la Fuente de Pedro Naharro (Cuenca), fue uno 
Pedro Narro [sic], dirigida al señor Director con fecha de 29 de marzo último, con que envía para la Academia tres medallas de plata de pequeño módulo, la una dentada, perteneciente al IIIviro monedero descendiente de M. Aquilio, y las otras dos celtibéricas de letras desconocidas y ambas de un mismo sello e inscripción.

Se acordó se pasen al señor Guevara para que, después de examinadas, las coloque en nuestro monetario en la serie que les corresponda y que al señor cura se le conteste por Secretaría dándole las gracias".

Las dos monedas celtibéricas son, sin duda, dos denarios. Respecto a la tercera pieza, la primera de las descritas, parece responder al siguiente tipo:

REPÚBLICA ROMANA. Denario; serratus. ROMA. 71 a.C.

A. Busto de Virtus, con casco, a derecha; delante, VIRTVS; detrás, IIIVIR.

R. Guerrero sosteniendo escudo con su mano izquierda y levantando con su derecha a una figura caída; debajo, SICIL; a la derecha, MN ·AQVIL; a la izquierda, $\underline{\mathrm{MN}} \cdot \mathrm{F} \cdot \underline{\mathrm{MN}} \cdot \mathrm{N}$.

RRC 401 .

\section{CERRO DE SAN JUAN DEL VISO (ALCALÁ DE HENARES, MADRID). MAYO DE 1791}

Acta de la Junta ordinaria de 3 de junio de 1791.

"El señor Cornide"11 regaló para la Academia una moneda de Segobriga, de cobre, con la cabeza de Tiberio con la leyenda IMP CAES DIVI AVG F AVGVSTVS y, en el reverso, SEGOBRIGA. Se halló en 31 de mayo último en el cerro de S. Juan del Viso, media legua al S.O.E. de Alcalá, donde se cree estuvo la antigua Complutum ${ }^{12}$, en cuyo sitio se hallan ruinas antiguas".

La pieza descrita parece la siguiente:

TIBERIO. As? SEGOBRIGA. 14-37 d.C.

de los colaboradores habituales de la Real Academia de la Historia en el estudio de las antigüedades de Segobriga tras las excavaciones de Antonio Tavira y Juan Antonio Fernández en 1789. Como Correspondiente se le encargó tutelar las actividades de Cornide para facilitar su trabajo. Escribió varias obras sobre las ruinas de Segobriga, principalmente dedicadas a la identificación de los prelados enterrados en la basílica visigoda y a rechazar las tesis de Manuel Risco. Cf. Abascal y Cebrián 2005, 257.

11. José Cornide Saavedra. Sobre su figura, cf. Abascal y Cebrián, 2009, con la bibliografía anterior tanto referida a la vida del autor como a sus obras; cf. también Fort, 1868.

12. Se transcriben en cursiva los subrayados del original.
A. TI CAESAR DIVI AVG F AVGVST IMP VIII. Cabeza desnuda (a izquierda o derecha).

R. SEGO / BRIGA, dentro de corona de roble. RPC 473 ó 474.

\section{CERRO DE SAN JUAN DEL VISO (ALCALÁ DE HENARES, MADRID). MAYO DE 1791}

Acta de la Junta ordinaria de 17 de junio de 1791].

"El señor Cornide regaló para la Academia dos medallas, la una de plata de pequeño módulo y otra de cobre de mediano, halladas en el cerro de San Juan del Viso al S.O.E. de Alcalá, en el mismo paraje donde se encontró la de Segobriga ${ }^{13}$ y ambas son de las desconocidas, aplicándose la de plata a Almántica y la otra a Celsa. Y se acordó que, sacándose cédula para el catálogo del monetario, se coloquen en él, como se hizo, dándose gracias al señor Cornide".

No es posible identificar la primera pieza citada, que parece un denario celtibérico. La segunda, atribuida a Celsa, parece una moneda de bronce de una ceca celtibérica que debería responder a la siguiente descripción:

KELSE. Unidad o as. Siglo II a.C.

A. Cabeza masculina, a derecha, con delfín detrás (o rodeada por tres delfines).

R. Jinete con lanza (o palma), a derecha; debajo, inscripción ibérica kelse.

\section{SANTA ENGRACIA (PANCORBO, BURGOS). GN 1864/4(5) [1794]. Figura 3}

Hallazgos casuales en Santa Engracia, descritos por Cándido María Trigueros ${ }^{14}$. Informe autógrafo de Cándido María Trigueros ${ }^{15}$ :

"Sobre dos medallas celtibéricas remitidas a examen por S. M.

En la Academia de 26 de diciembre de 1794

Parecer de Don Cándido María Trigueros

13. Se transcriben en cursiva los subrayados del original.

14. Orgaz, 4 de septiembre de 1736 - Madrid, 20 de mayo de 1798. Escritor, cervantista y anticuario, fue también autor de una abultada obra poética. Dedicó gran parte de su atención al mundo de las antigüedades y transcribió numerosos documentos en los Reales Estudios de San Isidro y en diferentes bibliotecas sevillanas y madrileñas.

15. Citada en Martín, Cepas y Canto, 2004, 277. Como puede verse por las diferencias de fechas entre la de redacción y la del expediente, el documento está fuera del lugar que le correspondería. 


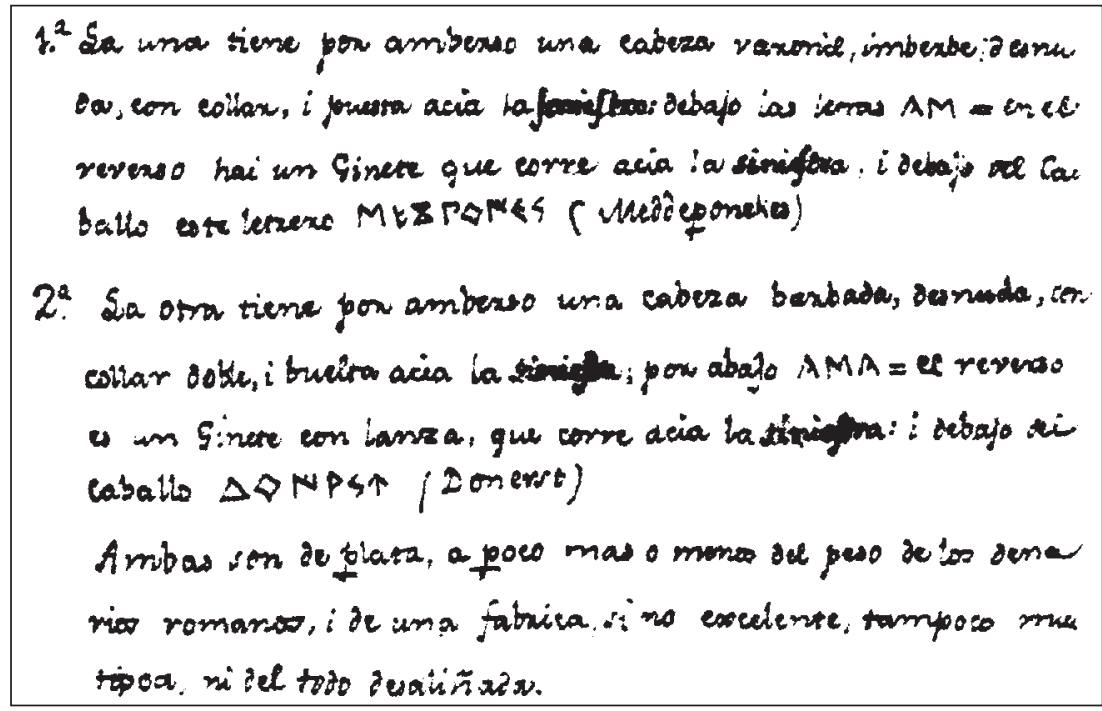

Figura 3: Fragmento del informe de Trigueros (GN 1864/4-5) sobre los dos denarios de Pancorbo.

Habiéndose dignado S. M. (que Dios guarde) de remitir a examen de su Academia de la Historia dos medallas antiguas de plata, que acaban de encontrarse al hacer unas excavaciones en el lugar de Santa Engracia para ciertas obras de arquitectura militar, ha insinuado, por medio de su primer Secretario de Estado, en oficio de 5 del corriente diciembre, que deseaba oir el dictamen de la Academia sobre los dichos monumentos; y la Academia, para mejor cumplir con el mandato de S. M., entre otras prevenciones ha tomado la de oir por escrito mi parecer sobre las citadas medallas con las razones o testimonios en que se funda; obedezco a la Academia con la mayor brevedad posible.

Estas dos medallas son de aquellas que, por la forma de sus caracteres, se llaman celtibéricas, aunque suelen hallarse no sólo en la Celtiberia sino en toda España, para distinguirlas de las que están señaladas con caracteres fenicios o púnicos y de las que, por encontrarse en la Bética y constar de letra más complicada y diversa de las demás, suelen decirse turdetanas.

[Siguen elogios al Marqués de Valdeflores y diversas conjeturas sobre el significado de algunas leyendas y sobre sus referencias étnicas]

Con arreglo a este supuesto, aplico mis principios a las dos medallas que ahora examino y digo en pocas palabras mi dictamen sobre ellas.

1. ' La una tiene por anverso una cabeza varonil, imberbe, desnuda, con collar y puesta hacia la siniestra; debajo las letras [caracteres celtibéricos]. En el reverso hay un jinete que corre hacia la siniestra y debajo del caballo este letrero [caracteres celtibéricos] (Meddeponekes) [Cf. Fig. 3].

2. ${ }^{\mathrm{a}}$ La otra tiene por anverso una cabeza barbada, desnuda, con collar doble y vuelta hacia la siniestra; por abajo [caracteres celtibéricos]. El reverso es un jinete con lanza que corre hacia la siniestra y debajo del caballo [caracteres celtibéricos] (donerst) [Cf. Fig. 3].

Ambas son de plata, a poco más o menos del peso de los denarios romanos y de una fábrica, si no excelente, tampoco muy tosca ni del todo desaliñada.

Tras la descripción de estas dos piezas, Trigueros se extiende con diversos comentarios sobre monedas celtibéricas que no transcribimos.

Las fichas de Trigueros corresponden a las siguientes piezas:

1. ${ }^{a}$ SEKOBIRIKES. Denario. Fines del siglo II - inicios del I a.C.

A. Cabeza masculina, a derecha; detrás, creciente; debajo, signo ibérico s; puede presentar tres, dos, uno o ningún punto entre el creciente y el cuello.

R. Jinete con lanza, a derecha, con o sin clámide y con un solo pie o los dos del jinete visibles; debajo, sobre línea, leyenda en caracteres ibéricos sekobirikes.

CNH, p. 292, n. ${ }^{\circ}$ 5-10; RAH, pp. 220-229.

2. TURIASU. Denario. Fines del siglo II a.C.

A. Cabeza barbada, a derecha, con torques; detrás, signo ibérico ka; debajo del cuello, s, y delante, tu.

R. Jinete con lanza, a derecha; debajo, sobre línea, leyenda ibérica turiazu.

Gozalbes, grupo V, p. 198; CNH, p. 256, n. ${ }^{\text {o }} 31-34$.

HELLIIN, CORRAL RUBIO (ALBACETE)

Y COFRENTES (VALENCIA). 1830-1831. EXPEDIENTE GN 1830-1832/1 (DOCUMENTOS 1-19)

En noviembre de 1830 José Rodríguez Carcelén, vecino de Hellín (Albacete), entró en contacto con la Real 
Academia de la Historia para ofrecer la donación de una serie de manuscritos inéditos de diferentes personajes, que estimada podían interesar en la Corte. Era aquel un primer contacto de quien cinco años más tarde tendría una activa participación en la recuperación del sarcófago romano de Hellín, lo que le valdría el nombramiento como académico correspondiente en abril de $1835^{16}$.

La correspondencia de Rodríguez Carcelén, fechada en Hellín entre noviembre de 1830 y noviembre de $1831^{17}$ trató fundamentalmente sobre esos envíos de manuscritos y el obsequio a la Academia de ciertos lotes de monedas descubiertos en las comarcas surorientales de Albacete, que habían llegado a manos del autor.

Esos lotes procedían de los parajes de El Castillejo (Corral Rubio, Albacete), El Pardo (Hellín, Albacete) y de Cofrentes (Valencia). Las circunstancias posteriores impidieron a Rodríguez Carcelén enviar a Madrid todas las monedas y hubo de conformarse con remitir las piezas descubiertas en Hellín y Cofrentes.

Presentamos a continuación la documentación conservada en la Academia sobre los hallazgos y su donación y trataremos de identificar luego las piezas cuando ello sea posible. Las referencias de los documentos son las del G(abinete) del N(umario) de la Real Academia de la Historia.

GN 1830-1832/1(1). Hellín, 8 de noviembre de 1830. Carta de José Rodríguez Carcelén a Martín Fernández de Navarrete, Director de la Academia, ofreciéndole a través de "mi amigo e individuo de esa Real Academia.... Don Sebastián Miñano... algunas de las obras inéditas de Don Pedro de Cantos Benítez". Ofrece adicionalmente tres tomos en folio relativos "a la causa del Maestro Froilán, confesor de Carlos $2 .^{\circ}$ y el tercero sobre el destierro del inquisidor general", así como "una obra en un tomo menor" sobre la "reducción de las diferentes clases de monedas". El escrito se leyó en la Junta ordinaria de 19 de noviembre y se acordó darle las gracias, advirtiéndole que algunas de esas obras estaban ya impresas.

GN 1830-1832/1(2). Madrid, 20 de noviembre de 1830. Minuta de la respuesta al escrito anterior.

GN 1830-1832/1(3). Hellín, 29 de noviembre de 1830. Carta de José Rodríguez Carcelén a Martín Fernández de Navarrete, Director de la Academia, dándole las gracias por la respuesta anterior y reafirmando el interés de los libros que ofrece, que son diferentes a los editados hasta ese momento. Luego, pasa a informar de algunos hallazgos monetarios:

16. Los detalles de esa recuperación y de la relación con Rodríguez Carcelén han sido explicados en Abascal y Abad (en prensa).

17. Citada en Martín, Cepas y Canto, 2004, 197-199.
"Hace un mes que en el pueblo de Corral Rubio, jurisdicción de la ciudad de Chinchilla y distante de esta villa cinco leguas, en un sitio llamado El Castillejo, donde las casas están fundadas sobre ruinas de los árabes, al hacer en una de ellas una pequeña excavación para formar una cantarera, se encontraron treinta monedas de oro perfectamente conservadas de las que sólo he podido recoger tres, que pongo a disposición de V.E. y lo haré de mayor número si puedo conseguir me las venda la persona que las ha comprado; su oro es muy puro, sus inscripciones muy claras; y las más de ellas, aunque de dos tamaños diferentes, iguales entre sí.

También pongo a disposición de V.E. otra de la misma clase, aunque de metal mezclado, encontrada por acaso, y diez y seis de varios metales inferiores y diversos tamaños, pertenecientes al Imperio romano y que se encontraron hace poco en una hacienda mía llamada El Pardo al plantar una viña, entre ruinas de edificios y sepulcros que contenían huesos o ánforas de barro común, llenas de cenizas humanas de las que sólo una ha salido entera, aunque con un golpe en su centro y falta del remate inferior que forma un tubo de pulgada y media de diámetro".

GN 1830-1832/1(4). Hellín, 30 de noviembre de 1830. Carta de José Rodríguez Carcelén a Diego Clemencín con la que adjuntaba el escrito n. ${ }^{\circ} 3$ para Fernández de Navarrete ${ }^{18}$. El texto fue leído en la Junta ordinaria del 3 de diciembre. En la carta, a propósito de las monedas se añade lo siguiente:

"Las monedas árabes las ha comprado la mayor parte Don Joaquín Maldonado, yerno del difunto Don Pedro Macanaz ${ }^{19}$, que accidentalmente se halla en ésta y del que veré si puedo conseguir algunas más. El dueño de la casa, que fue el que me las vendió, refiere que su abuelo se encontró una gran porción de monedas de oro y plata, que las vendió a los plateros que concurrían a la feria de Caravaca, de donde trajo dos yuntas de labor y otras cosas y después compró mucha hacienda. He averiguado

18. Martín Fernández de Navarrete Jiménez de Tejada (Ábalos, La Rioja, 9 de noviembre de 1765 - Madrid, 8 de octubre de 1844). Formado en el seminario de Vergara y marino de profesión, fue miembro del Consejo de Estado, Director de la Real Academia de la Historia (1825-1844) y Académico de la Española (1792), de la de San Fernando (1792), de la Sevillana de Buenas Letras, San Carlos de Valencia (1817), San Luis de Zaragoza (1826) y de otras extranjeras. Fue autor de algunos estudios fundamentales de historia de la Marina y editor del Quijote; escribió poesías, diversos ensayos y una Ortografía de la lengua castellana. Dejó inéditos una gran cantidad de informes y una copiosa correspondencia con decenas de personajes de su generación

19. Emparentado con el célebre Melchor de Macanaz, Pedro Macanaz fue ministro de Gracia y Justicia de Fernando VII en 1814. 
si era esto verdad y lo es en realidad. El ánfora la conservo y la remitiré si así se me previene".

GN 1830-1832/1(5). Hellín, 18 de diciembre de 1830. Carta de José Rodríguez Carcelén a Antonio Siles ${ }^{20}$ informándole que por medio de un correo ordinario ha enviado a la Academia, a través de la Secretaría de Estado, varios libros y "una cajita con las monedas". El escrito fue leído en Junta el 22 de diciembre.

GN 1830-1832/1(6). Madrid, 22 de diciembre de 1830. Minuta de un oficio de la Academia a la Secretaría de Estado informando del envío de José Rodríguez Carcelén, para que se autorice la entrada de los objetos en Madrid y la entrega a la Academia.

GN 1830-1832/1(7). Madrid, 4 de enero de 1831. Oficio de Manuel González Salmón a la Academia, comunicando que se han dado las órdenes para que los obsequios de José Rodríguez Carcelén puedan entrar en Madrid y sean entregados a la Academia. Leído en Junta ordinaria de 7 de enero de 1831 .

GN 1830-1832/1(8). Madrid, 7 de enero de 1831. Minuta de oficio a José Rodríguez Carcelén para indicarle que no se ha recibido en Madrid su envío y que haga las averiguaciones correspondientes para evitar su pérdida.

GN 1830-1832/1(9). Hellín, 15 de enero de 1831. Carta de José Rodríguez Carcelén a la Academia, indicando que todo se entregó por error en el Gabinete de Historia Natural pero que pronto llegará a la Academia. El escrito fue leído en Junta el 21 de enero.

GN 1830-1832/1(10). Madrid, 29 de enero de 1831. Minuta de oficio a José Rodríguez Carcelén para indicarle que ya se han recogido los libros y las monedas.

GN 1830-1832/1(11). [1831]. Documento anónimo, sin fecha, con la lista de los libros enviados por José Rodríguez Carcelén que ya posee la Academia.

GN 1830-1832/1(12). Madrid, 17 de marzo de 1831. Informe de la comisión nombrada para examinar los manuscritos y monedas remitidos desde Hellín por D. José Rodríguez Carcelén, leído en la Real Academia de la Historia el día 18 de marzo de 1831.

“... Informada ya la Academia del contenido de los cuatro manuscritos, pasaremos a decir alguna cosa

20. Antonio Siles $(†$ 1834). Abogado y catedrático de Disciplina Eclesiástica. Ingresó como supernumerario en la Real Academia de la Historia en 1801 y fue dado de baja por Real Orden de 16 de octubre de 1814. Se anuló su baja en 1820 y en 1832 ascendió a numerario, siendo anticuario y bibliotecario de la Academia desde 1833 hasta su muerte. Cf. Vargas Zúñiga, 1978, 89-90. de las monedas remitidas juntamente con ellos. Éstas son veinte y una, las diez y siete romanas, todas de cobre, las restantes arábigas, de las cuales tres son de oro y una de mezcla; de todas ellas hablaremos por orden cronológico.

1. ${ }^{\text {a }}$ Está mal conservada; en el anverso se ve la cabeza de Augusto laureada y sólo puede leerse DIVI F y en el reverso tiene un buey sobre el cual se lee con dificultad BACCIO; en el exergo MN FESTO y delante II VIR, por cuyos caracteres conviene perfectamente con la publicada por el Maestro Flórez (tab. 16 núm. 1) perteneciente a la colonia de Celsa y no dudamos que sea la misma.

2. Se ha conservado bastante bien mas, por haber caído el cuño fuera de la moneda, sólo se ve en el anverso la cabeza desnuda de Augusto, un ramo de palma muy mal figurado y, de la inscripción, DIVI $\mathrm{D}$; $\mathrm{y}$ en parte opuesta únicamente tiene el laberinto sin inscripción; cuyos caracteres convienen en un todo a la publicada por el mismo P. Flórez (tab. 16 núm. 9) y aplicada a Carthago Nova, hoy Cartagena.

3. ${ }^{\text {a }}$ Del emperador Claudio, cuya cabeza desnuda aparece en el anverso con la inscripción TI CLAVDIVS CAESAR AVG P M TR P IMP P P $\mathrm{y}$, en el reverso, una figura de mujer en pie con las manos extendidas, en el área $\mathrm{S} \mathrm{C}$ y alrededor LIBERTAS AVGVSTA, cuya moneda es muy parecida a la del núm. 24 de las de este emperador que pone Gússeme en su Diccionario numismático, aunque no es del todo conforme.

4. ${ }^{a}$ Del emperador Tito, con su cabeza laureada en el anverso y la inscripción T CAESAR IMP COS II CENS y, en la parte opuesta, una mujer en pie con la cornucopia en la mano derecha (en la izquierda no se percibe lo que tiene), en el área S C y alrededor FELICITAS PVBLICA. Tampoco esta moneda es la misma aunque sí muy parecida a la del núm. 31 entre las de este emperador que trae Gússeme en su Diccionario.

5. ${ }^{\text {a }}$ Del emperador Domiciano, en cuyo anverso se ve su cabeza laureada y la inscripción IMP CAESAR DIVI VESP F DOMITIAN AVG P M y en el reverso, que está mal conservado, se ve a Palas en pie con lanza en la derecha pero no se percibe lo que tiene a la izquierda, ni de la inscripción se puede leer más que el $\mathrm{S} \mathrm{C}$ del área y alrededor DES VIIII P mas, sin embargo, por estos caracteres conviene con la del núm. 106 entre las de este emperador del diccionario de Gússeme.

6. ${ }^{\text {a }}$ Del emperador Gordiano Pío, con su cabeza laureada y la inscripción IMP GORDIANVS PIVS FEL AVG en el anverso y, al lado opuesto, una mujer sentada con un ramo en la mano derecha, la izquierda sobre la silla, en el exergo S C y, alrededor, P M TR P V COS; y lo demás no se puede leer. Sin duda es la del núm. 45 que pone Gússeme en este emperador.

7. a Del emperador Aureliano, cuya cabeza coronada de radios presenta el anverso con la inscripción 
IMP AVREALIANVS AVG y en el reverso se ve al emperador y a su mujer, Severina, dándose la mano, con la inscripción CONCORDIA MILITVM y, en el exergo, *P; y así la trae Gússeme con corta diferencia entre las de este emperador núm. 9.

8. ${ }^{\mathrm{a}}$ Del emperador Caro, con su cabeza coronada de rayos en el anverso y la inscripción IMP C M AVR CARVS P F AVG y, en el lado opuesto, ANNONAAVGG, una mujer en pie con una espiga en la mano derecha, la cornucopia en la izquierda, el modio a sus pies y, en el exergo, R B. Es la del núm. 5 entre las de este emperador que pone Gússeme.

9. ${ }^{\text {a }}$ Del emperador Maximiano, con su cabeza coronada de rayos y la inscripción IMP C M A MAXIMIANVS P F AVG en el anverso y, en la parte contraria, CONCORDIA MILITVM, Júpiter y el emperador teniendo en las manos una victoriola y, entre los dos, K B. La trae Gússeme y es la del núm. 15 de las de este emperador.

10. ${ }^{a}$ Del emperador Constantino, cuya cabeza laureada está en el anverso mas, por estar cortada, se lee con trabajo CONSTANTINVS MAX AVG; y en el reverso tiene dos figuras en pie con lábaros y la inscripción GLORIA EXERCITVS pero están cortadas las letras del exergo. Es la del núm. 46 que pone Gússeme de este emperador.

11. ${ }^{\mathrm{a}}$ Del mismo emperador, con la inscripción IMP CONSTANTINVS P F AVG y su cabeza laureada en el anverso; y en el reverso PRINCIPI IVVENTVTIS, una figura paludada en pie con un signo militar en cada mano, a sus lados $\mathrm{S}$ A y, en el exergo, PTB. Se diferencia bastante de la del núm. 67 del diccionario de Gússeme.

12. ${ }^{\text {a }}$ Del mismo, con su cabeza laureada en el anverso y la inscripción IMP CONSTANTINVS P F AVG y, en el reverso, el sol desnudo y en pie con la mano derecha levantada; en la izquierda, un globo y la cabeza coronada de rayos; alrededor, la inscripción SOLI INVICTO COMITI; en el área T $\mathrm{F}^{*} \mathrm{y}$, en el exergo, TARL. La pone Gússeme aunque con alguna diferencia y es la 86 del emperador Constantino.

13. ${ }^{\text {a }}$ Del mismo pero está tan desgastada que en el anverso se ve su cabeza y sólo puede leerse...VS P F AVG y, en la parte opuesta, al emperador en pie, con lábaro en la derecha y globo en la izquierda y de la inscripción sólo puede leerse ROMANORVM, así como tampoco las letras del exergo.

14. ${ }^{\text {a }}$ Está muy desgastada pero parece del mismo; en el anverso se ve una cabeza y no puede leerse la inscripción y en el reverso sólo se lee GLORIA... pero no las letras del exergo y se ve una figura en pie, con lanza en la derecha, y en la izquierda no se percibe.

15. ${ }^{\text {a }}$ Parece del mismo; en el anverso hay una cabeza con corona de perlas pero está muy desgastada la inscripción y en el reverso se ve al emperador con el lábaro en la derecha y en la izquierda no se conoce bien; la inscripción, GLORIA ROMANORVM y, en el exergo, S H H A.

16. ' De Constantino el joven, con su cabeza laureada en el anverso y la inscripción CONSTANTINVS IVN NOB C y en reverso una matrona con galea, sentada sobre clípeo, con otro en la mano, en el XV; en el área, P B; en el exergo, R P y la inscripción ROMAE AETERNAE. Es la del núm. 20 de las de este emperador en el diccionario de Gússeme.

17. a Del emperador Graciano; tiene en el anverso su cabeza con corona de perlas y la inscripción D N GRATIANVS P F AVG y en el reverso está el emperador en pie, teniendo en la izquierda un globo con victoriola y dando la mano a una mujer arrodillada y coronada de torres, con la inscripción REPARATIO REIPVB y en el exergo SCON. La trae Gússeme en su diccionario y es la del núm. 8 que pone de este emperador.

Ninguna de estas monedas es rara, ni por la mayor parte están bien conservadas; en cambio de ésto, son en extremo curiosas las cuatro árabes cuya interpretación, hecha por nuestro revisor actual, oimos con sumo gusto en la sesión anterior. Acreedor es por lo tanto D. José Rodríguez Carcelén a que la Academia se muestre agradecida a su buena memoria, dándole por ello las consabidas gracias y congratulándose con la adquisición de unos manuscritos sobremanera apreciables y de unas monedas seguramente dignas de no menor estimación con que se aumenta la colección copiosa y escogida que de unos y otras posee.

Madrid, 17 de marzo de 1831.

\section{José Sabau y Blanco ${ }^{21}$ [rubricado] Pedro Sáinz de Baranda $^{22}$ [rubricado]"}

GN 1830-1832/1(13). Madrid, 19 de marzo de 1831. Minuta de oficio a José Rodríguez Carcelén para indicarle que los libros y las monedas ya obran en poder de la Academia.

GN 1830-1832/1(14). Hellín, 7 de junio de 1831. Carta de José Rodríguez Carcelén a la Academia, avisando

21. Tamarite de Litera, Huesca 1757 - Madrid 1833. Canónigo de Burgos, Arcediano en la catedral de Zaragoza y Obispo electo de Osma en 1833. Ingresó en la Real Academia de la Historia en 1819 como Supernumerario, fue Censor de libros de Historia y en 1820 se convirtió en su Anticuario. Desde 1823 ocupó plaza de Numerario y llegó a ser Bibliotecario y Archivero Perpetuo hasta su muerte. Entre otros trabajos literarios, se ocupó de la reedición de la Historia General de España de Mariana. Sobre su figura, cf. Vargas Zúñiga, 1978, 98-99, n. ${ }^{\circ}$ 98; Almagro-Gorbea, 1999, 132.

22. 1797-Madrid 1853. Académico Supernumerario (1830) y luego de Número de la Real Academia de la Historia (18451853) y su Bibliotecario durante casi 20 años (1834-1853), puesto que ocupó incluso siendo aún Supernumerario. 
de nuevos hallazgos de monedas. El escrito fue leído en Junta el 10 de junio.

"Constante siempre en adquirir todo lo que pueda ser de alguna utilidad para V.E., lo acabo de hacer de dos monedas de plata, la una del emperador Trajano, cuyo hermoso busto es de un relieve extraordinario y en el reverso representa un personaje con una ropa talar y una flor en la mano; la otra representa un carro con dos caballos en el acto de galopar y, entre sus pies y manos, dice Safras y, bajo de la raya que figura el pavimento, Roma. En el reverso parece ser una figura de escorpión. La primera no he podido averiguar su origen y la segunda se ha encontrado en la jurisdicción de la villa de Cofrentes, reino de Valencia. Igualmente he adquirido siete u ocho monedas de cobre, también romanas, todas las que remitiré a V.E. a la mayor brevedad".

El texto continua con el aviso de que Joaquín Maldonado, yerno de Pedro Macanaz, ha vendido casi todos los manuscritos de Melchor Macanaz, que se pueden dar por perdidos; Carcelén ha podido recuperar una pequeña parte que enviará a la Academia.

GN 1830-1832/1(15). Madrid, 11 de junio de 1831. Minuta de oficio a José Rodríguez Carcelén para darle las gracias por su oferta de nuevos obsequios.

GN 1830-1832/1(16). Hellín, 28 de octubre de 1831. Carta de José Rodríguez Carcelén a Diego Clemencín, informando del envío de las monedas y libros prometidos. A continuación relata un nuevo hallazgo monetario:

"Ayer compré otra moneda de oro de 28 gramos de peso, la que parece nueva y de los godos; tenga U. la bondad de decirme si la remitiré por el correo..."

El escrito fue leído en Junta el 4 de noviembre y se acordó darle las gracias y aceptar el obsequio.

GN 1830-1832/1(17). Madrid, 18 de noviembre de 1831. Minuta de oficio a José Rodríguez Carcelén para comunicar la recepción de una moneda de Trajano, de un denario romano y de seis monedas de "cobre", al tiempo que se acepta su oferta de regalar una nueva moneda de oro.

GN 1830-1832/1(18). Madrid, 13 de diciembre de 1831. Minuta de oficio a José Rodríguez Carcelén con la que se le envía la descripción de las monedas árabes que había regalado a la Academia el año anterior.

GN 1830-1832/1(19). [Madrid, 13 de diciembre de 1831]. Descripción resumida de las monedas árabes regaladas por José Rodríguez Carcelén, tomada de las Actas de la Academia y del informe de la comisión.
Los conjuntos monetarios y ejemplares aislados a los que alude la correspondencia son los siguientes:

A. Corral Rubio (Albacete), paraje del Castillejo. Conjunto de 30 monedas árabes de oro descubiertas en octubre de 1830 "en un sitio llamado El Castillejo, donde las casas están fundadas sobre ruinas de los árabes, al hacer en una de ellas una pequeña excavación para formar una cantarera"; el autor pudo comprar tres de ellas (GN 1830-1832/1, documento 3). En la carta del día siguiente, 30 de noviembre de 1830 (GN 1830$1832 / 1$, documento 4) indica que la mayor parte del conjunto lo compró "Don Joaquín Maldonado, yerno del difunto Don Pedro Macanaz" y que el dueño de la casa "refiere que su abuelo se encontró una gran porción de monedas de oro y plata, que las vendió a los plateros que concurrían a la feria de Caravaca". Rodríguez Carcelén envió sus tres monedas a la Academia el 18 de diciembre (GN 1830-1832/1, documento 5) y se entregaron en la Academia el 29 de enero de 1831 (GN 1830-1832/1, documento 10).

B. Cofrentes (Valencia). Denario republicano comprado por Rodríguez Carcelén y ofrecido a la Academia el 7 de junio de 1831 (GN 1830-1832/1, documento 14), donde se recibió el 18 de noviembre de ese año (GN 1830-1832/1, documento 17). La pieza responde a la siguiente descripción:

REPÚBLICA ROMANA. Denario. ROMA. 150 a.C. A. Cabeza de Roma, con casco, a derecha; detrás, X. R. Victoria en biga, a derecha, sosteniendo látigo con su mano derecha y riendas con la izquierda; debajo, SAFRA; en exergo, ROMA.

RRC, 206.

Procedencia: Cofrentes (Valencia).

Bib.: Chaves 2005, 261. No es posible saber a cuál de los cinco ejemplares del monetario actual se refiere.

C. Hellín (Albacete), paraje de El Pardo. Conjunto de 17 monedas romanas descubiertas "hace poco en una hacienda mía llamada El Pardo al plantar una viña, entre ruinas de edificios y sepulcros que contenían huesos o ánforas de barro común, llenas de cenizas humanas de las que sólo una ha salido entera, aunque con un golpe en su centro y falta del remate inferior que forma un tubo de pulgada y media de diámetro", según carta de Rodríguez Carcelén de 29 de noviembre de 1830 (GN 1830-1832/1, documento 3). Fueron enviadas a la Academia el 18 de diciembre (GN 18301832/1, documento 5) y se entregaron allí el 29 de enero de 1831 (GN 1830-1832/1, documento 10).

Las monedas citadas, descritas sumariamente por José Sabau y Blanco y Pedro Sáinz de Baranda en marzo de 1831 (GN 1830-1832/1, documento 12) son las siguientes:

1. AUGUSTO. As. CELSA. 27 a.C. - 14 d.C.

A. [augustus] - DIVI F. Cabeza laureada, a derecha. 
R. [c v i cel 1] BAGGIO MN FESTO IIVIR. Toro a derecha.

RPC 273.

2. AUGUSTO. As. Ceca del noroeste (Lugo). Post 27 a.C.

A. [imp aug] DIVI F. Cabeza desnuda, a izquierda; delante, palma; [detrás, caduceo alado].

R. Escudo redondo.

RPC 3-4. La serie consta de sestercios, dupondios y ases. Al no indicarse el peso, no es posible precisar el tipo exacto de la pieza. El autor describe el reverso como laberinto, por la forma y grabado del escudo; los dupondios tienen espada y puñal a ambos lados del escudo, lo cual no se indica y podría descartarse este valor. Quizá la clave pueda estar en la referencia que hace al tipo de Flórez, aunque tampoco es seguro.

3. CLAUDIO. As. ROMA o ceca local. 50-54 d.C.

A. TI CLAVDIVS CAESAR AVG P M TR P IMP P P. Cabeza desnuda, a izquierda.

R. LIBERTAS AVGVSTA, S - C. Libertas en pie, sosteniendo pileus con su mano derecha y extendiendo la izquierda.

RIC $\mathrm{I}^{2}, 113$.

4. VESPASIANO, emisión a nombre de TITO. Dupondio. ROMA. 73 d.C.

A. T CAESAR IMP COS II CENS. Cabeza radiada, a derecha.

R. FELICITAS PVBLICA, S - C. Felicitas de pie, a izquierda, sosteniendo caduceo y cornucopia.

RIC II, 648 (b). El autor indica cabeza laureada en anverso, cuando en realidad es radiada. Eso se explica porque en algunas monedas de este período los rayos de la corona apenas son perceptibles, sobre todo si tienen algún desgaste. En el reverso indica que la cornucopia está en la mano derecha de la figura, cuando lo correcto sería decir en "su" mano izquierda.

5. DOMICIANO. Sestercio, dupondio o as. ROMA. 82 d.C.

A. IMP CAES DIVI VESP F DOMITIAN AVG P M. Cabeza laureada (no se indica si a derecha o a izquierda).

R. [tr $p \cos$ VIII] DES VIIII P [p], S - C. Minerva en pie con lanza en la mano derecha (-).

RIC II, p. 184. La leyenda de anverso existe en la forma abreviada CAES pero no como CAESAR, por lo que debe haber un error en la descripción. No sabemos si quiere decir que la lanza está en la parte derecha del campo o en la mano derecha de Minerva; hay una gran cantidad de variantes en anverso y reverso, con la dificultad añadida de que los dupondios, que en esta época son radiados, existen en esta serie también con láurea.

6. GORDIANO III. Sestercio o as. ROMA, 4. ${ }^{\mathrm{a}}$ serie. 241-243 d.C.
A. IMP GORDIANVS PIVS FEL AVG. Busto laureado, drapeado y con coraza, a derecha.

R. P M TR P V COS [II p p]. Apolo sentado, a izquierda, sosteniendo rama con su mano derecha y apoyando su codo izquierdo sobre lira.

Exergo: S C

RIC IV.3, 303. Al no conocer el peso no podemos precisar la identidad de la pieza, pues el tipo se encuentra en las dos denominaciones. En el reverso cita por error a una mujer, lo que se explica porque Apolo en estas piezas parece, efectivamente, una figura femenina.

7. AURELIANO. Antoniniano. SISCIA, período II, of. 1. ${ }^{\text {a }}$. 270-275 d.C.

A. IMP AVRELIANVS AVG. Busto radiado, a derecha.

R. CONCORDIA MILITVM. Emperador, de pie a derecha, dando la mano a Concordia, que está de pie hacia la izquierda.

Exergo: * $\mathrm{P}$

RIC V.1, 216. El busto de anverso tiene dos variantes, con drápea o con coraza, pero este extremo no puede precisarse con los datos del autor.

8. CARO. Antoniniano. ROMA, serie 1. ${ }^{\mathrm{a}}$, of. 2. ${ }^{\mathrm{a}}$. 282283 d.C.

A. IMP C M AVR CARVS P F AVG. Busto radiado, con coraza, a derecha.

R. ANNONA AVGG. Annona, de pie a izquierda, sosteniendo espigas con su mano derecha y cornucopia en la izquierda; a sus pies, modio.

Exergo RB

RIC V.2, 37.

9. MAXIMIANO. Nummus. CYZICO, of. 2. . 295299 d.C.

A. IMP C M A MAXIMIANVS P F AVG. Busto radiado, a derecha.

R. CONCORDIA MILITVM. Emperador, de pie a derecha, recibiendo victoriola sobre globo de Júpiter, que está de pie a izquierda, apoyado en su cetro con su mano izquierda.

Exergo: KB//-

RIC VI, 15b ó 16b. La clasificación con dos opciones depende de la variante de anverso, ya que el busto puede ser sólo con coraza o drapeado y con coraza. En el reverso la leyenda partida puede ser MI-LITVM ó M-IL ó MIL-I.

10. CONSTANTINO. Nummus. Ceca?. 330-336 d.C. A. CONSTANTI-NVS MAX AVG. Busto laureado, a derecha.

R. GLOR-IA EXERC-ITVS. Dos soldados en pie con lanzas y escudos; entre ellos, dos estandartes.

No se indica exergo por estar las letras cortadas, según el autor. Al describir el reverso se habla de lábaros, en plural, lo que es fundamental para saber que se trata de Constantino y no de su hijo Constantino II, en 
quien aparecen estas leyendas a partir del año 337 pero con un solo estandarte. La leyenda partida del anverso existe en todas la cercas. La cabeza laureada que se describe, sólo existe en Lugdunum, Treveris y Cyzico, con bustos drapeados y con coraza en las tres cecas y una variante en Cyzico con coraza únicamente. La leyenda partida del reverso la tienen también todas las cecas.

11. CONSTANTINO. Follis. TREVERIS, of. 1. . $307-$ 308 d.C.

A. IMP CONSTANTINVS P F AVG. Busto laureado, a derecha.

R. PRINCIPI - IVVE-NTVTIS (ó PI-IV-VE). Emperador en pie, con un estandarte militar en cada mano. Exergo: S / A // PTR

RIC VI, 780-783. Los números corresponden a las cuatro variantes posibles de busto: drapeado visto desde atrás, con coraza, drapeado y con coraza o drapeado y con coraza visto desde atrás.

12. CONSTANTINO. Nummus. ARELATE, of. 3. ${ }^{\mathrm{a}}$. 316 d.C.

A. IMP CONSTANTINVS P F AVG. Busto laureado, a derecha.

R. SOLI INVICTO COMITI. Sol en pie, levantando su mano derecha y sosteniendo globo con la izquierda. Exergo: T* / F /TARL

RIC VII, 80-81 u 84-85 (p. 241). En 80-81 la posición del Sol es a izquierda; en 84-85, a derecha. Ambos números de cada posición indican la doble opción de anverso, que puede ser drapeado y con coraza o sólo con coraza. La leyenda del reverso podría ser partida, como ocurre en muchas variantes (RIC VII, p. 241).

13. TEODOSIO, ARCADIO u HONORIO. AE 2. Ceca oriental. 392-395 d.C.

A. [-]VS P F AVG. Busto diademado, drapeado y con coraza, a derecha.

R. [gloria] - ROMANORVM. Emperador en pie, sosteniendo estandarte y globo.

El autor indica que no pueden leerse las letras del exergo. En el anverso, la diadema e perlas está presente en todas las cecas; Antioquía y Alejandría tienen variante con rosetas.

14. ATRIBUCIÓN INDETERMINABLE. AE2 o nummus. Ceca? Siglo IV d.C.

A. [-]. Cabeza.

R. GLORIA [-]. Figura en pie con lanza en la derecha $(-)$.

Exergo: [-]

Existen varios tipos con inicio de leyenda en la forma GLORIA. La descripción de una figura en pie con lanza en la derecha, igual podría corresponder a un estandarte gastado de GLORIA - ROMANORVM como, a modo de ejemplo, a un tipo GLORIA -EXERCITVS de Constantinopla, RIC VII 16 ó 22. No hay datos suficientes para precisar la identidad de la pieza.
15. TEODOSIO, ARCADIO u HONORIO. AE 2. HERACLEA o NICOMEDIA. 392-395 d.C.

A. [-]. Busto con diadema de perlas, drapeado y con coraza, a derecha.

R. GLORIA - ROMANORVM. Emperador en pie, sosteniendo estandarte [y globo].

Exergo: SMHA ó SMNA.

RIC IX, 27 (Heraclea) ó 46 (Nicomedia).

La segunda letra del exergo es una $\mathrm{M}$ en lugar de la $\mathrm{H}$ que indica el manuscrito y la tercera puede ser tanto una $\mathrm{H}$ como una $\mathrm{N}$, pues ambas se prestan a confusión.

16. CONSTANTINO II. Nummus. ROMA, of. 1. 318-319 d.C.

A. CONSTANTINVS IVN NOB C. Busto laureado, drapeado y con coraza, a derecha.

R. ROMAE A-ETERNAE. Roma sentada a derecha, sosteniendo sobre su regazo un escudo con la inscripción $\mathrm{X} / \mathrm{V}$.

Exergo: P / R // RP

RIC VII, 156.

La leyenda partida del reverso es la única conocida para la oficina primera; las tres restantes oficinas tienen alguna variante. La letra del campo derecho es una $\mathrm{R}$ y no una $\mathrm{B}$, como dice el autor.

17. GRACIANO. AE2. ARELATE, of. 2. . 378-383 d.C.

A. D N GRATIA - NVS P F AVG. Busto con diadema de perlas, drapeado y con coraza, a derecha.

R. REPARATIO - REIPVB. Emperador en pie, levantando con su mano derecha a una mujer arrodillada con cabeza torreada, y sosteniendo victoriola sobre globo con su izquierda.

Exergo: SCON

RIC IX, 20a.

\section{Sin procedencia}

Denario adquirido por Rodríguez Carcelén en junio de 1831 (GN 1830-1832/1, documento 14), que ingresó en la Academia el 18 de noviembre de ese año (GN 1830-1832/1, documento 17).

1. TRAJANO. Denario. ROMA. 103-114 d.C. A. IMP TRAIANO AVG GER DAC P M TR P (COS V P P / COS VI P P). Busto laureado, a derecha.

R. (COS V P P) S P Q R OPTIMO PRINC(IPI). Spes andando a izquierda y sosteniendo flor.

RIC II, 127, 191 ó 279. Las letras y números que colocamos entre paréntesis son las posibles variantes de estas tres monedas, que el autor omite la descripción de las leyendas de anverso y reverso.

\section{E. Sin procedencia}

Moneda "de oro de 28 gramos de peso, la que parece nueva y de los godos", comprada por Rodríguez Carcelén el 27 de octubre de 1831 (GN 1830-1832/1, documento 16, de 28 de octubre); la ofreció a la Academia, donde no consta que ingresara. 
Prof. Dr. Juan M. Abascal Palazón

Área de Historia Antigua

Dpto. Prehistoria, Arqueología

$\mathrm{H}^{\text {a }}$ Antigua, Filología Griega y Filología Latina

Universidad de Alicante

03080 Alicante

juan.abascal@ua.es

Antonio Alberola Belda

Explanada de España, $8,1^{\circ} \mathrm{B}$

03001 Alicante

\section{BIBLIOGRAFÍA}

ABASCAL, J.M. y ABAD, L., en prensa: "El descubrimiento y recuperación del sarcófago romano de Hellín. Una aventura arqueológica decimonónica”, en Homenaje al Prof. Julio Mangas (en prensa).

ABASCAL, J.M. y CEBRIÁN, R., 2005: Manuscritos sobre antigüedades de la Real Academia de la Historia, Madrid.

ABASCAL, J.M. y CEBRIÁN, R., 2009: Los viajes de José Cornide por España y Portugal de 1754 a 1801, Madrid.

ABASCAL, J.M. y CEBRIÁN, R., 2010: José Vargas Ponce en la Real Academia de la Historia, Madrid.

ALMAGRO-GORBEA, M., 1999: "El Gabinete de Antigüedades de la Real Academia de la Historia", en M. ALMAGRO-GORBEA (ed.), El Gabinete de Antigüedades de la Real Academia de la Historia, 15-173, Madrid.

ANÓNIMO, 1796: "Noticia del origen, progresos y trabajos literarios de la Real Academia de la Historia", Memorias de la Real Academia de la Historia, 1, I-CLXI.

BRUUN, P.M., 1966: RIC VII. Constantine and Licinius (A.D.313-337), London (repr. 1984).

BURNETT, A., AMANDRY, M. y RIPOLLÈS, P.P. 1992: Roman Provincial Coinage, vol. I, Londres-Paris.

CHAVES, F., 2005: Monedas romanas I. La República. Real Academia de la Historia. Catálogos del Gabinete de Antigüedades, Madrid.

CNH. Vid. Villaronga, 1994.

CRAWFORD, M.H., 1974: Roman Republican Coinage, Cambridge (19872).

FLÓREZ, E., 1757-1773: Medallas de las colonias, municipios y pueblos antiguos de España. Colección de las que se hallan en diversos autores, y de otras nunca publicadas con explicación y dibujo de cada una, Madrid, 3 vols.

FORT Y PAZOS, C.R., 1868: Discurso en elogio de Don José Cornide de Saavedra. Secretario que fue de la Real Academia de la Historia, leído en la Junta Pública que celebró este Cuerpo á 7 de junio de 1868, por su individuo de número y bibliotecario Don -, Madrid.
HERMOSILLA DE SANDOVAL, I., 1796: "Noticia de las ruinas de Talavera la Vieja, leida en la Academia de 2 de julio de 1762", Memorias de la Real Academia de la Historia, 1, 345-362.

KENT, J.P.C., 1981: RIC VIII. The family of Constantine I (A.D. 337-364), London.

MAIER, J., 2003: "II Centenario de la Real Cédula de 1803. La Real Academia de la Historia y el inicio de la legislación sobre el patrimonio arqueológico y monumental en España”, Boletín de la Real Academia de la Historia, 200, 437-473.

MARTÍN ESCUDERO, F., CEPAS, A. y CANTO, A., 2004: Archivo del Gabinete del Numario. Catálogo e índices. Real Academia de la Historia, Madrid.

MATTINGLY, H. ET ALII, 1949: RIC IV.3. Gordian IIIVranius Antoninus, London.

MATTINGLY, H. y SYDENHAM, E.E., 1926: RIC II. Vespasian to Hadrian, London (repr. 1972²).

MATTINGLY, H. y SYDENHAM, E.E., 1930: RIC III. Antoninus Pius to Commodus, London.

PEARCE, J.W.E., 1933: RIC IX. Valentinian I-Theodosius I, London (repr. 1972).

$R A H$. Vid. Ripollès y Abascal, 2000.

RIC I². Vid. Sutherland, 1984.

RIC II. Vid. Marringly y Sydenham, 1926.

RIC III. Vid. Marringly y Sydenham, 1930.

RIC IV.3. Vid. Mattingly et alii, 1949.

RIC IX. Vid. Pearce, 1933.

RIC V.1. Vid. Webb, 1927.

RIC V.2, Vid. Webb, 1933.

RIC VI. Vid. Sutherland, 1967.

RIC VII. Vid. Bruun, 1966.

RIC VIII. Vid. Kent, 1981.

RIPOLLÈS, P.P. y ABASCAL, J.M., 2000: Monedas hispánicas. Real Academia de la Historia. Catálogos del Gabinete de Antigüedades, Madrid.

RPC. Vid. Burnett et alii, 1992.

RRC. Vid. Crawford, 1974.

SUTHERLAND, C.H.V., 1967: RIC VI. Fron Diocletian's reform (A.D. 294) to the death of Maximinus (A.D.313), London (repr. 1984).

SUTHERLAND, C.H.V., 1984: RIC I. From 31 BC to AD 69, London, 2. ${ }^{\mathrm{a}}$ ed.

VILLARONGA, L., 1994: Corpus Nummum Hispaniae ante Augusti Aetatem, Madrid.

VARGAS-ZÚÑIGA Y MONTERO DE ESPINOSA, A. (Marqués de Siete Iglesias), 1978: "Real Academia de la Historia. Catálogo de sus individuos. Noticias sacadas de su Archivo", Boletín de la Real Academia de la Historia, 175, 19-105, 309-352 y 533-574.

WEBB, P.H., 1927: RIC V.1. Valerian to Florian, London. WEBB, P.H., 1933: RIC V.2. Probus to Amandus, London. 